\title{
Contributo para a geodesia das culturas da infância: brincadeiras na latitude $0^{\circ}$ e $41^{\circ}$
}

\author{
Contributions to childhood culture's geodesy: playing at $0^{\circ}$ end $41^{\circ}$ latitude
}

\section{Contribución a la geodesia de las culturas infantiles: juegos en latitud $0^{\circ}$ y $41^{\circ}$}

\author{
Marlene Barra* \\ Manuela Sampaio Pinto*
}

\section{Resumo}

\begin{abstract}
Uma exposição fotográfica sobre as brincadeiras das crianças de São Tomé e Príncipe (latitude $0^{\circ}$ ) e as brincadeiras das crianças de Portugal (latitude $41^{\circ}$ ) são o mote para refletir sobre a promoção universal Direito a BRINCAR e a plena participação cultural das crianças nas suas sociedades, expressos nos n⿳ 1 e 2 do artigo $31^{\circ}$ da Convenção dos Direitos da Criança de 1989, respetivamente. Na análise das brincadeiras dessas crianças, é possível o (re) conhecimento dos lugares a partir dos quais as crianças vêm o mundo e atribuem significado ao que as rodeia. Ou seja, o mapeamento dos tempos, lugares e das formas como se cruzam o mundo adulto e o mundo infantil ou como são constituídas as culturas da infância. Aqui se sugere que proclamar, respeitar e promover o direito universal da criança a brincar só terá sentido se todos os esforços para a concretização desse direito se basearem na ideia de localização das brincadeiras das crianças.
\end{abstract}

Palavras-chave: Direitos da Criança. Culturas da Infância. Brincadeiras.

\section{Abstract}

A photographic exhibition about São Tomé and Príncipe children's play (latitude $0^{\circ}$ ) and the play of children from Portugal (latitude $41^{\circ}$ ) is the motto to reflect on the promotion of the Universal Right to play and the full cultural and social participation of children, expressed in Article 31 (number 1 and 2) of the 1989 Convention on the Rights of the Child, respectively. Analysing children's play it was possible to recognize the places from which children see the world and give meaning to their surroundings. That is, the mapping of time, place, and the way in which are intersect the adult and the child's world and constituted childhood's cultures. Proclaiming, respecting and promoting children's universal right to play, this article suggests, only makes sense if all these efforts are based on the idea of locating children's play.

Keywords: Rights of the Child. Childhood Cultures. Pranks.

Recebido em 11/10/2019 - Aprovado em 08/02/2020

http://dx.doi.org/10.5335/rep.v27i2.11436

\begin{abstract}
Doutora em Estudos da Criança pelo Instituto de Educação da Universidade do Minho, é colaboradora no Centro de Recursos para a Cooperação e Desenvolvimento do IE-UMinho e no Centro de Investigação em Estudos da Criança da UMinho. Trabalhou em diversos projetos internacionais, tal como a reestruturação do Programa Educativo Nacional da Guiné-Bissau e a implementação do primeiro curso de Educação de Infância na Universidade Pública de Timor-Leste. Consultora na UNICEF de São Tomé e Príncipe entre 2016 e 2018, foi responsável pelo desenho e implementação do Programa de Educação Parental (MEAS-DPSS), alargado a todo o país em 2020. Orcid: https://orcid. org/0000-0002-1196-2956. E-mail: marlenebarra2016@gmail.com

** Doutora em Estudos da Criança. Educadora de Infância e Coordenadora do Departamento de Educação Pré-escolar e Coordenadora da EMAEl (Educação Inclusiva) no Agrupamento de Escolas Amadeo de Souza Cardoso, Amarante, Portugal. Professora Coordenadora no Instituto Superior de Ciências Educativas do Douro, Penafiel, Portugal. Orcid: https://orcid.org/0000-0002-1294-3597.E-mail: mansampaio@gmail.com
\end{abstract}




\section{Resumen}

Una exposición fotográfica sobre el juego de niños de Sao Tomé y Príncipe (latitud $0^{\circ}$ ) y el juego de niños de Portugal (latitud $41^{\circ}$ ) es el lema para reflexionar sobre la promoción universal del derecho al juego y la plena participación cultural de los niños en la sociedad, expresadas en el Artículo 31 (números 1 y 2) de la Convención sobre los Derechos del Niño de 1989, respectivamente. En el análisis del juego de estos niños, es posible (re) conocer los lugares de donde los niños ven el mundo y dar significado a su entorno. Es decir, el mapeo de los tiempos, lugares y las formas en que el mundo adulto y el mundo infantil se cruzan, o donde se constituyen las culturas de la infancia. En este artículo se sugiere que proclamar, respetar y promover el derecho universal de los niños a jugar solo tendrá sentido si todos los esfuerzos para realizar este derecho se basan en la idea de ubicación del juego de los niños.

Palabras-clave: Derechos del niño. Culturas de la infancia. Juegos.

\section{Introdução}

O presente artigo converge para a reflexão sobre o $31^{\circ}$ artigo da Convenção sobre os Direitos da Criança (1989), ou sobre o Direito de Brincar, partindo da análise de algumas imagens sobre a prática da ludicidade protagonizada por crianças habitantes em latitudes distintas: as crianças santomenses da latitude $0^{\circ}$ e as crianças portuguesas da latitude $41^{\circ}$. A inspiração para realizar o encontro entre estes dois mundos das crianças surge também do encontro entre duas educadoras de infância e investigadoras em sociologia da infância: as imagens das crianças que nutrem o presente texto foram capturadas no contexto de recolha de dados de duas investigações de doutoramento em Estudos da Criança, na área da Sociologia da Infância ${ }^{1}$ : sobre as brincadeiras das crianças santomenses - latitude $0^{\circ}$ - e o trabalho quotidiano ${ }^{2}$ num Jardim de Infância da rede pública portuguesa - latitude $41^{\circ}$. Esses registos "funcionam" aqui como "pontos de partida" para a análise e "molas inspiradoras" para as reflexões que aqui se adiantam (MALINOWSKI, 1974). Com este exercício pretendemos lançar luz sobre as formas como a "gramática das culturas da infância" (SARMENTO, 2004, p. 22) se exprime nas duas latitudes por meio das brincadeiras das crianças. Ou seja, pretende-se contribuir para o mapeamento dos tempos, lugares e das formas como se cruzam o mundo adulto e o mundo infantil ou como são constituídas as culturas da infância.

Num primeiro momento, faremos algumas considerações sobre o direito da criança a brincar e a sua relação com as culturas da infância, explicitando seguidamente as dimensões da "gramática das culturas da infância" (SARMENTO, 2004, p. 22). Finalmente, com base nos registos fotográficos resgatados junto das crianças que brincam em São Tomé e Príncipe (latitude $0^{\circ}$ ) e junto das crianças que 
brincam em Portugal (latitude $41^{\circ}$ ), refletiremos sobre os significados, princípios e regras, processos e formas subjacentes e constituintes das brincadeiras das crianças santomenses e portuguesas.

\section{0 direito de brincar e as culturas da infância}

O direito de brincar está consagrado no Artigo $31^{\circ}$ da Convenção sobre os Direitos da Criança (1989), onde se lê nos números 1 e 2:

1. Os Estados Partes reconhecem à criança o direito ao repouso e aos tempos livres, o direito de participar em jogos e atividades recreativas próprias da sua idade e de participar livremente na vida cultural e artística.

2. Os Estados Partes respeitam e promovem o direito da criança de participar plenamente na vida cultural e artística e encorajam a organização, em seu benefício, de formas adequadas de tempos livres e de atividades recreativas, artísticas e culturais, em condições de igualdade.

Que o brincar faça parte do tempo designado para se viver a infância é hoje visto como essencial no mundo ocidental: ser criança é brincar (CALLOIS, 1958; HUIZINGA, 1954; DENZIN, 1977; LOPES, 1998; AMADO, 2002) e os tempos e espaços para que as crianças brinquem estruturam-se como meios para proteger as crianças (TOMÁS; FERNANDES, 2014) ou como garantia para que as crianças vivam plenamente os dias da infância (FERREIRA, 2004). As mudanças a que estão sujeitas todas as sociedades na contemporaneidade (na família, nas instituições, nas tecnologias de informação e comunicação, no mercado global de produtos para as crianças, etc.), e, consequentemente, nas vidas das crianças, modificam, dificultam ou impedem que muitas crianças brinquem. A ideia que essencializa o brincar das crianças - como intrínseco à natureza das crianças e realizado de forma espontânea e livre - é paradoxal com a normalização e excessiva regulamentação a que estão sujeitas as brincadeiras na contemporaneidade (SILVA, 2011; TOMÁS; SOARES, 2011; UN-CDC, 2013). Dessa forma, fica também obscurecido aquilo que de facto significa brincar e, sobretudo, aquilo que no brincar é significante para as crianças.

De acordo com o ponto de vista que assumimos no presente texto, brincar é a atividade dominante nas vidas das crianças: não como uma preparação para as suas futuras vidas adultas, mas como a construção presente das suas vidas de crianças (CORSARO, 1985, 1997; JAMES, 1993, 1998; BROUGÉRE, 1994; SARMENTO, 2004; FERREIRA, 2004). Ou seja, entendemos que a "participação plena das crianças na vida cultural das suas sociedades” ( $n^{\circ} 2$ do artigo $31^{\circ}$ da CDC, 1989) 
se realiza quando o direito a brincar é promovido com respeito ao contexto social de pertença de cada uma das crianças. Assim, torna-se indispensável a promoção do diálogo entre as culturas da infância e os direitos da criança com o firme propósito de se conhecer, localmente, para se criticar (e construir) no âmbito de um quadro global (BURMAN, 1996). Entendemos por culturas da infância os processos simbólicos postos em ação pelas crianças, gerados na relação das culturas societais a que pertencem com as culturas de pares, através dos quais procedem à interpretação do mundo e ao desenvolvimento das suas práticas sociais (CORSARO, 2002; DELALANDE, 2004; SARMENTO, 2004). As culturas infantis surgem das interações entre as crianças e os seus grupos de pares e entre as crianças e os adultos, ou seja, entre as culturas próprias das crianças e as culturas dos adultos (CORSARO, 1997) que sofrem, por sua vez, influências de outras culturas, variadas, plurais, globais e até contraditórias. Falar em várias culturas infantis esclarece a sua diversa produção, ou seja, a sua (re)construção na interação com as diferentes culturas da sociedade onde se inserem assim como na inter-relação entre geração, classe, gênero e etnia (SARMENTO, 2003). É na convergência destes universos relacionais que são geradas as culturas da infância na sua globalidade e pluralidade e assim são entendidas como diferentes, e não como menores ou inferiores como são muitas vezes cunhadas pelo discurso adultocêntrico e pelo discurso etnocêntrico (FERREIRA; SARMENTO, 2008; KOPPELE, 2012; COLONNA, 2012; SARMENTO, 2013; ROCHA; COSTA, 2014; BARRA, 2016).

O brincar é entendido como um dos pilares fundamentais das culturas da infância (SARMENTO, 2003; 2004), uma atividade social muito significativa no espaço temporal da infância e central na construção de visões individuais ou coletivas, ou na reprodução interpretativa do mundo (CORSARO, 2002). Entendemos que a análise das práticas e significados relacionados com a brincadeira e os brinquedos utilizados pelas crianças podem aproximar-nos das suas culturas e dos sistemas de construção dos modos de significação e de ação intencional das crianças no mundo (SARMENTO, 2003). Por outras palavras, os modos como as crianças recebem as diferentes formas culturais que chegam até elas, como as interpretam e reproduzem nos seus universos sociais, em suma, como é que as crianças se caracterizam enquanto fruidores e criadores culturais distintos dos adultos.

Seguimos então o trilho das brincadeiras, costumes lúdicos, jogos tradicionais, universais e/ou geracionais das crianças santomenses e portuguesas na tentativa de mapear os lugares das culturas da infância. A "gramática das culturas da infância” proposta por Manuel Sarmento (2004) pode auxiliar-nos na identificação 
destes lugares de criação ou na topografia das culturas lúdicas nas latitudes $0^{\circ} \mathrm{e}$ $41^{\circ}$ contribuindo, mais amplamente, para a geodesia das culturas da infância - tal como anunciado no título deste artigo.

\section{A gramática das culturas da infância}

A "gramática das culturas da infância" (SARMENTO, 2004) sugere a existência de princípios lógicos e regras que estruturam as culturas que são próprias das crianças, ou da infância, embora em simbiose com os mundos adultos. Levando em conta essa metáfora gramatical no estudo das culturas da infância poderemos capitulá-la em:

- Semântica das culturas da infância, que diz respeito aos processos de referenciação e significação elaborados e entendidos pelos/entre os membros deste grupo geracional;

- Sintaxe que dita as regras de articulação entre os elementos simbólicos mobilizados nos mundos de vida das crianças;

- Morfologia que apresenta as formas singulares e os processos específicos de formação dos elementos constitutivos das culturas da infância;

- Pragmática que explicita as relações de comunicação e os processos de cooperação e estratificação entre as crianças nos contextos.

A identificação e análise dessas dimensões da gramática das culturas da infância, no sentido de definir e delinear os princípios e traços que as distinguem das culturas adultas, implica ter em conta os "quatro eixos estruturadores das culturas da infância" (SARMENTO, 2004, p. 14) propostos pelo autor: a interatividade, a ludicidade, a fantasia do real e a reiteração.

- A interactividade, como um dos eixos estruturadores das culturas da Infância, é concebida no mundo da criança no "plano sincrónico e no plano diacrónico" (JAMES, JENKS; PROUT, 1998) e não pode ser compreendida fora do contexto das interações do mundo adulto. Essa interação é particularmente visível nos jogos e brincadeiras das crianças, que partilhados ou proporcionados no contexto de interação com os pares, no quotidiano das crianças, são passíveis de reprodução por diversas gerações de crianças, condicionadas sempre pelos diversos contextos históricos, sociais e culturais de onde emergem. Esta situação é particularmente reveladora de comportamentos "infantis", pois, muitas vezes, os adultos não têm acesso ao que "está na 
moda" em determinado momento no mundo das crianças. No entanto, a interação sistemática que se manifesta está envolta num processo que transforma tanto as formas como a criança "controla" o mundo adulto, como nas formas que os adultos encontram de administrar os mundos das crianças e de onde procedem, afinal, muitas das ideias que os adultos possuem acerca daquilo que é especificamente infantil ou não.

- A ludicidade constitui-se também como um traço fundamental e distintivo das culturas da Infância, manifestando-se recorrentemente nas atividades diárias das crianças quando ela brinca com tudo e tudo lhe serve para brincar e, assim, diversão e jogos são assuntos sérios para a criança, ou aquilo que ela faz de mais sério e interessante. $O$ culto da ludicidade, ou a cultura lúdica, constitui-se como o referencial da própria ideia de Infância, ou daquilo que é "infantil", embora por vezes extremamente naturalizado, e constituem-se como basilares na (re)produção que as crianças fazem do mundo, assim como na (re)construção dos seus próprios universos.

- A fantasia do real é, no âmbito das culturas infantis, "fundacional do modo de inteligibilidade" (SARMENTO, 2002, p. 15), ou seja, dos modos de vida das crianças no mundo. A "transposição imaginária" das situações vivenciadas, das pessoas que coabitam no universo da criança ou daquilo que a rodeia, constitui-se como um modo específico de "ser criança" e um elemento central de reforço da sua capacidade de resistência e entendimento do mundo, que se lhe deparam por vezes de formas muito confusas ou dolorosas. $\mathrm{O}$ "pensamento fantasista" característico do universo infantil está, por exemplo, presente nas (re)configurações que faz dos objetos: "Agora faz de conta que isto é..."; ou "...é de mentirinha" são sentenças tipicamente infantis na língua portuguesa, paradigmáticas das suas formas de brincar, representar ou apropriar-se da realidade que a rodeia. Segundo Manuel Sarmento, a criança fá-lo na sua luta "[...] contra todos os determinismos e contra todas as pretensões de subordinação a um controle total, para uma ordem habitável, e sendo o faz de conta processual permite à criança continuar o jogo da vida em condições aceitáveis" e inteligíveis para ela própria (SARMENTO, 2002, p. 15).

- A reiteração, como o quarto eixo estruturante das culturas da Infância, revela também a especificidade dos mundos da Infância pela constatação de que o "tempo" para a criança não é linear, constituinte de uma ordem, ele será antes "recursivo". Esse tempo da Infância exprime-se, tal como a in- 
teratividade de que anteriormente se falou, no plano sincrónico quando a criança recria continuamente as mesmas situações e acontecimentos. Este tempo sem medida é repetidamente investido de novas possibilidades, podendo ser iniciado e/ou repetido, quando a criança desejar. Nesse processo, se constroem "fluxos de (inter)ação", estruturantes de práticas ritualizadas ou como motivo de ruturas nas atividades das crianças, que reestruturam as rotinas de ação onde são estabelecidos os protocolos de comunicação e reforçadas as regras das brincadeiras e jogos. As competências de interação assim adquiridas são transmitidas e repetidas no plano diacrónico, também quando se transmitem rituais, jogos e modos de brincar de uma geração de crianças para a seguinte. "Isto permite que seja toda a Infância que se reinventa e recria, começando tudo de novo" (SARMENTO, 2003, p. 16).

Estes quatro eixos estruturadores das culturas da Infância orientam a reprodução interpretativa do mundo pelas crianças, onde se cruzam as culturas locais (re)produzidas entre as crianças e a cultura global que emerge - quer infantis quer adultas. São processos manifestos transversal e cumulativamente nas brincadeiras das crianças de ambas as latitudes, tal como pode verificar-se no ponto que de seguida apresentamos.

\section{Brincadeiras nas latitudes $0^{\circ}$ e $41^{\circ}$}

Apresentam-se de seguida 16 imagens em que as crianças brincam nos dois contextos geográficos, aglutinados em 8 momentos que registam brincadeiras muito semelhantes, de acordo com o nosso ponto de vista. A análise incide sobre 1 - os significados de cada jogo ou brincadeira; 2 - as regras e princípios assumidos pelos grupos de crianças; 3 - as formas de que se revestem as brincadeiras e uso dos brinquedos; 4 - as (re)significações dos objetos para brincar e/ou brinquedos. 


\section{Os significados da brincadeira}

Figuras 1 e 2 - Brincadeiras com água
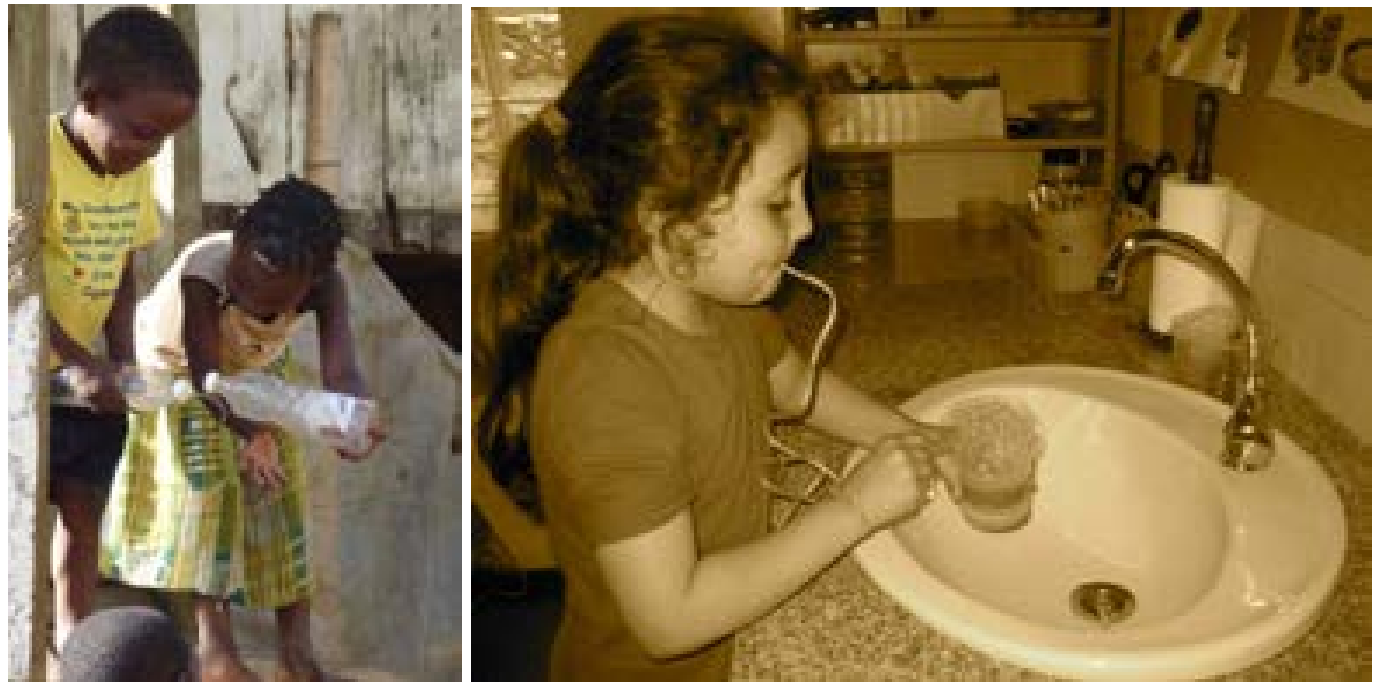

Fonte: registo das investigadoras.

A água exerce um fascínio sobre as crianças que, talvez, se deva às suas propriedades quase mágicas: ela muda de cor, gela, desaparece, etc. Será também no seio desses mistérios que as crianças interagem entre si trocando ideias, questionando possibilidades, fantasiando as descobertas e repetindo, uma e outra vez, as brincadeiras com água. Escolher a água para brincar, concentrar-se nesta atividade e divertir-se experienciando-a de diferentes formas são elementos comuns nestas imagens, capturadas em São Tomé e Príncipe (Figura 1) e em Portugal (Figura 2). No entanto, a reflexão sobre o contexto em que essa brincadeira é realizada permite-nos compreender mais profundamente sobre o seu significado em cada um dos mundos de vida dessas crianças: para a criança portuguesa que brinca, a água é considerada como mais uma ferramenta de aprendizagem disponível na torneira do lavatório da sua sala de atividades, onde existem vários materiais que equipam o espaço "laboratório" da sala e onde é promovida a sua manipulação e a experimentação de diversas formas pelas crianças (fazer bolhinhas, colocar vinagre, juntar tinta, soprar, vazar e fazer medições de volume, etc.); em São Tomé e Príncipe, as duas crianças brincam com duas velhas garrafas de vinagre cheias de água, que, sendo de plástico, podem ser apertadas para gotejar ou esguichar água aos com- 
panheiros. No contexto santomense, as crianças são muitas vezes instruídas pelos adultos sobre o dever de não brincar com a água, ou são mesmo proibidas, pois a água é um bem precioso que não corre nas torneiras das casas de muitas famílias santomenses. Ela tem que ser acartada desde as torneiras comunitárias ou desde os rios e riachos, chegando em ombros ou à cabeça com sacrifício, em recipientes maiores ou menores conforme o seu transporte é feito por adultos ou crianças (muitas vezes esta é tarefa dos meninos), e nas casas das famílias aguarda o destino de auxiliar a limpeza pessoal nos banhos, no lavar da loiça ou roupa, mas sempre com cuidado de não ser desperdiçada, não sendo contemplado/autorizado o seu uso nas brincadeiras das crianças.

Para as crianças de ambos os contextos a água é manipulada ludicamente, ou seja, é ela própria um brinquedo nas mãos das crianças (mesmo que "sagrada" em contexto de escassez) constituindo atividades lúdicas plenas de diversão. Aquilo que nessa brincadeira é diverso nos dois contextos é o significado da brincadeira: para as crianças portuguesas é uma brincadeira que pode suportar as suas descobertas e aprendizagens, são impulsionadas pelos adultos e orgulhosamente exibidas pelas crianças; para as crianças santomenses esta brincadeira específica com a água poderá ter um carater transgressor (AMADO, 2002), podendo mesmo ser repudiada ou proibida por algum adulto ou criança mais velha enquanto decorre.

Figuras 3 e 4 - Brincadeiras com o corpo
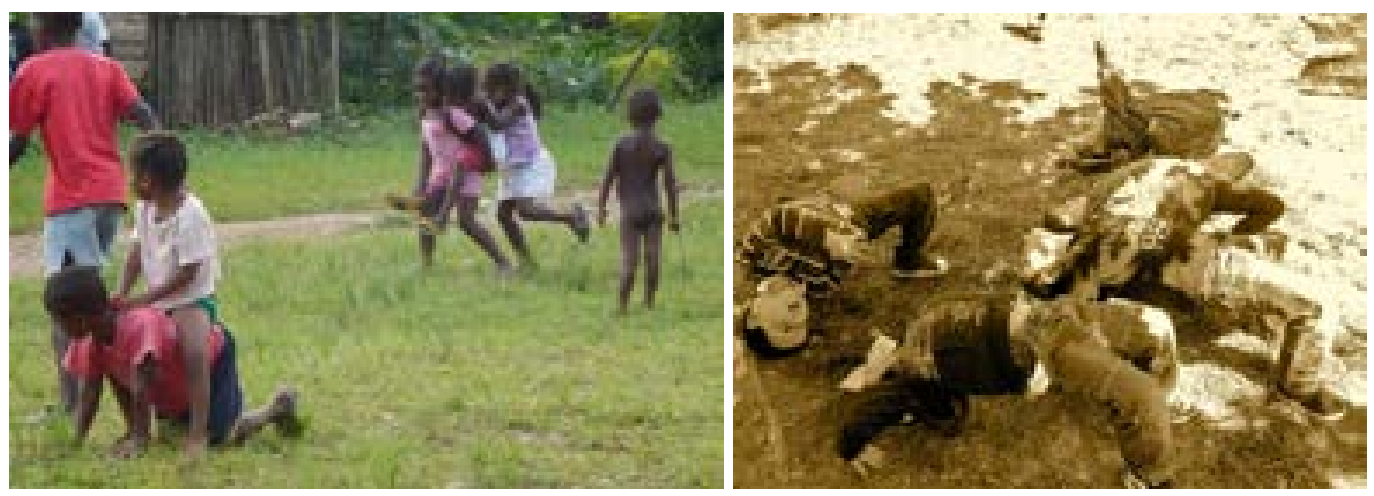

Fonte: registo das investigadoras.

Nas imagens selecionadas, são capturadas brincadeiras que as crianças realizam apenas com o próprio corpo, sem recurso a brinquedos, onde a exibição das suas habilidades, perícia na execução dos movimentos e divertimento na vertigem 
é visivelmente comum. Percebemos também que ambos os grupos fazem a recriação do real: nas movimentações das crianças santomenses poderemos perceber os papéis de "cavaleiros" e "cavalos"; "carregadores" e "cargas" (Figura 3) e no jogo lúdico das crianças portuguesas elas se esmeram na construção de criativas pontes com o corpo (Figura 4). Esse momento, aproveitado também pelo adulto que faz o registo, conversa sobre a atividade e tenta explorá-la com mais profundidade, acontece na espontaneidade do tempo de recreio destas crianças, porque foi assim que desejaram brincar, sem uma organização de suporte, a montante, por parte do adulto que, no caso, é espetador da organização grupal de crianças de duas salas e do modo como exploram o espaço com o próprio corpo, ludicamente. Para as crianças santomenses, brincar com o próprio corpo e/ou com o corpo dos seus pares é atividade lúdica muito frequente e rotineira nos seus quotidianos. Nessas brincadeiras, o brincar com os outros, e não com objetos, assume papel fundamental (SARMENTO, 2004) e a interatividade surge como fundadora de fantasias imaginadas e partilhadas pelas crianças santomenses. Socorrendo-nos de Gilles Brougère (2005) poderemos adiantar que se os adultos estão alheados da cultura lúdica infantil deste grupo de crianças julgarão como brigas, e até ofensas corporais, tais movimentações criativas e atividades de interação lúdica entre as crianças santomenses, pois desconhecem as referências que permitem interpretar estas atividades como brincadeiras e diferenciá-las de outras.

Para as crianças de ambos os contextos, os seus próprios corpos são assumidos como brinquedos e com eles são exercitadas formas lúdicas através da imaginação e do exercício físico criativo, possível sobretudo pela partilha de significados e regras entre as crianças. A diferença está no significado atribuído a esse tipo de brincadeiras, pois para as crianças santomenses o brincar com o próprio corpo e com o do outro como com brinquedos é frequente nas suas vidas quotidianas, sendo que o bligá faz parte das atividades recreativas tradicionais santomenses. Para as crianças portuguesas será uma brincadeira criativa, um exercício lúdico de criatividade, uma mostra de habilidades contorcionistas perante os companheiros. 


\section{Regras e princípios da brincadeira}

Figuras 5 e 6 - Brincadeiras de colecionar e jogar
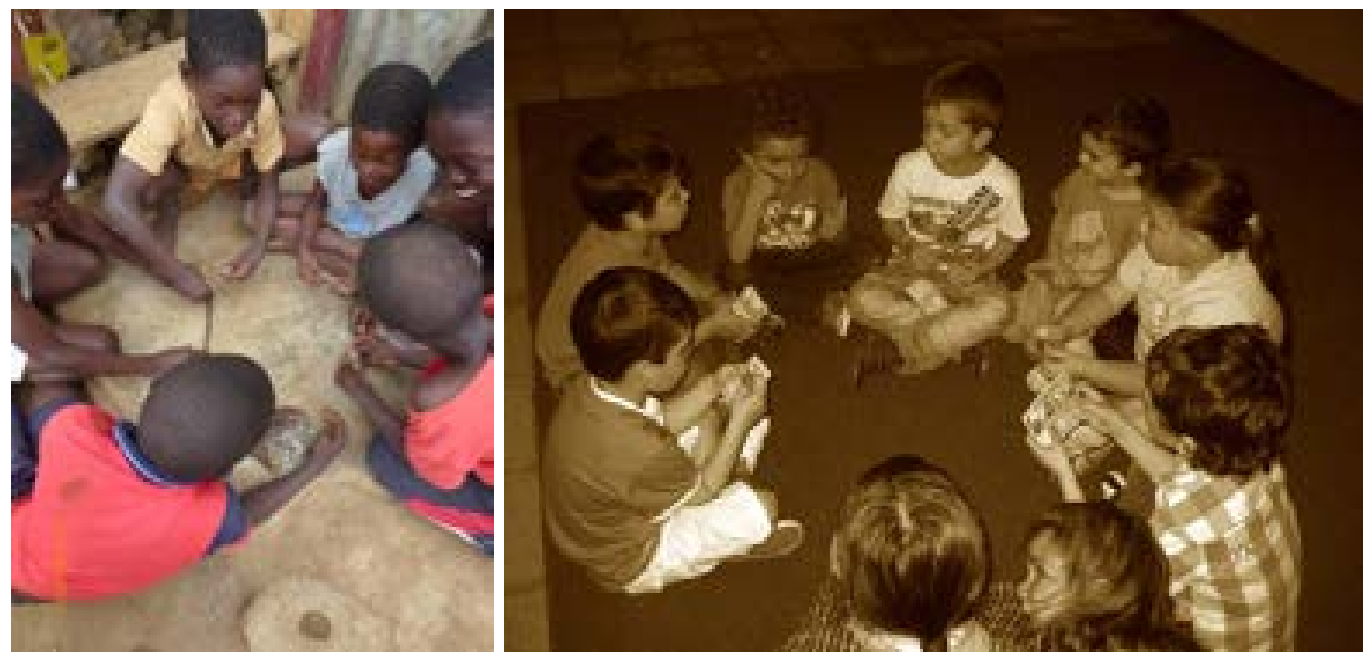

Fonte: registo das investigadoras.

Nas duas imagens selecionadas é possível verificarmos a presença de grupos de rapazes que, sentados em círculo, se concentram em alguns objetos que têm em mãos: as crianças santomenses negoceiam a troca de anilhas de latas de refrigerante e preparam-se para jogar chichi-cala (Figura 5); e as crianças portuguesas jogam numa imitação do jogo de cartas dos adultos, criando as suas próprias regras com os cromos do Pokémon (Figura 6). Em ambas as brincadeiras, ou jogos, está inscrita uma forma lúdica comum entre o género masculino: o gosto em possuir (poder), colecionar e trocar determinados elementos e divertir-se com os companheiros jogando com eles. Nesse jogo, aqueles itens transbordam de ludicidade, pois deixam de ser simples cartões impressos ou anilhas coloridas de refrigerantes para, de acordo com a sua configuração (forma, cor, tamanho ou quantidade) obterem significados diferentes e possibilitando a quem os possui (ou possui em maior quantidade): mais força, energia extra, ou um poder especial que podem levar à vitória no jogo anunciado e negociado.

Aquilo que é comum nas brincadeiras dessas crianças, para além do facto dela ser protagonizada por rapazes em ambos os contextos, são as regras assumidas pelos jogadores: coletar, colecionar, trocar e jogar com os melhores elementos possíveis para ganhar um jogo. Aquilo que difere são os meios, brinquedos ou elementos lúdicos em cada contexto, pois as cartas Pokémom consistem em brinquedos 
industriais mundialmente conhecidas e comercializadas, enquanto as anilhas das latas de refrigerante são materiais de desperdício reaproveitados pelas crianças, de acesso relativamente fácil e gratuito.

Figuras 7 e 8 - Brincadeiras com construções
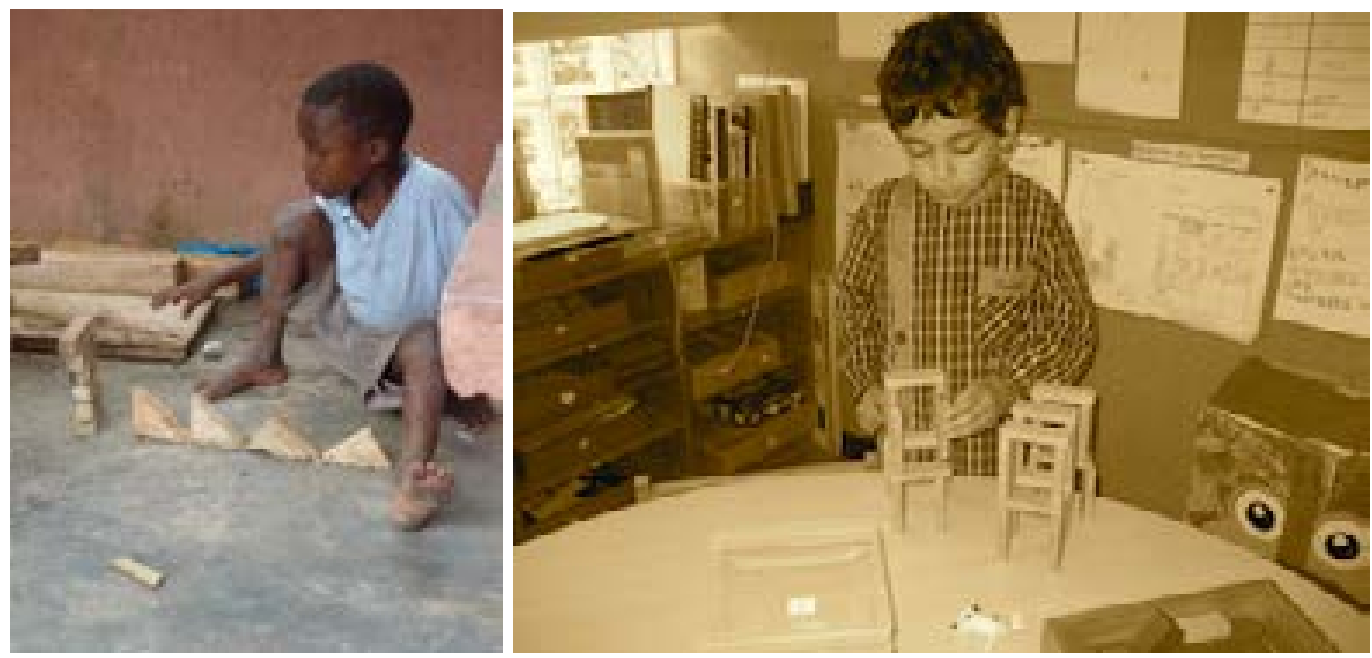

Fonte: registo das investigadoras.

Nas fotografias dessas duas crianças, é visível a sua concentração num jogo de construção com peças de madeira. A sua habilidade e criatividade dita a colocação de cada uma das peças e apenas a sua imaginação limitará a forma final que objetivam construir, ou as diversas construções (e destruições) que vão descobrindo ser possíveis. Ambos os rapazes, de idades aproximadas, escolhem brincar de forma similar com estas peças de madeira: contar, sequenciar, classificar, alinhar, empilhar, distribuir, etc.; permitindo-lhe a realização das experiências e configurações que desejam. Aparentemente parece-nos que apenas a estética, geometria dos elementos, e do cenário onde decorre a brincadeira, diferem nos contextos: a criança santomense brinca com pedaços de madeira em bruto no chão do refeitório da sua escola (Figura 8) e a criança portuguesa brinca com peças industriais polidas na mesa da sala de atividades da sua escola (Figura 8). A contextualização dessas brincadeiras revela-nos, no entanto, um mundo de diferenças entre as brincadeiras destas crianças: a criança santomense brinca com esses pedacinhos de madeira durante a observação e acompanhamento dos adultos que serravam tábuas para construir bancos para o refeitório da sua escola. A criança portuguesa encontra 
este jogo disponível, entre outros, na sua sala de atividades e escolhe fazer construções num dos tempos regulamentados para isso.

Aquilo que aproxima essas crianças, nessa atividade lúdica, é o patente gosto na concentração, imaginação, criatividade, etc. que este tipo de materiais e atividade permite e aquilo que as diferencia são os materiais utilizados assim como a oportunidade de o fazer - e fazendo-o - os significados que povoam o imaginário e as criações de cada um desses meninos nas suas realizações.

\section{Morfologia da brincadeira}

Figuras 9 e 10 - Brincadeiras na casinha
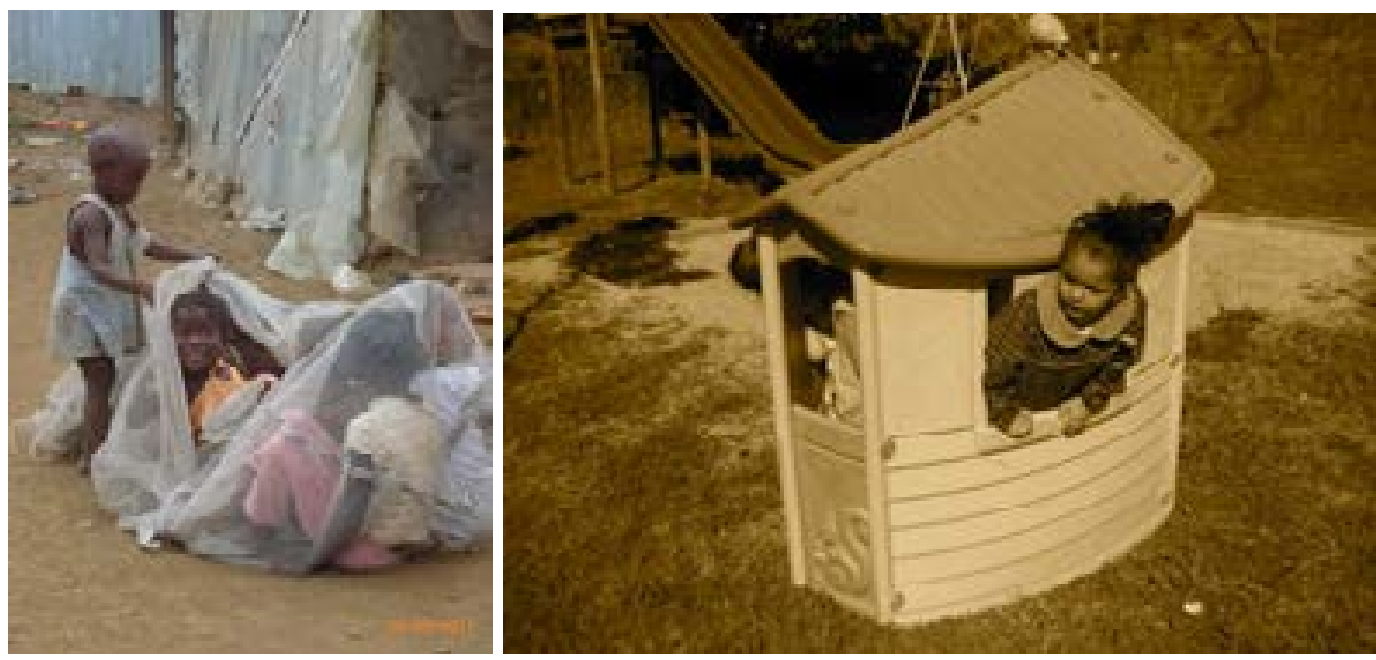

Fonte: registo das investigadoras.

Nas fotografias selecionadas, percebemos que estes pequenos grupos de crianças manipulam ludicamente diferentes materiais embora as suas posturas corporais e ações nos contem histórias com sentidos idênticos nas brincadeiras de faz de conta que protagonizam: na primeira imagem (Figura 9) as crianças santomenses envolvem-se numa velha rede mosquiteiro e acomodam-se no seu interior como numa casa que todos ocupam, mas que permite entrar e sair abrindo e fechando "as portas" e "janelas". As crianças portuguesas (Figura 10) partilham uma casinha de plástico no recreio da sua escola com os companheiros de faz de conta, entrando, saindo ou simplesmente "a ver as amigas no baloiço" ao apear-se na janela.

Aquilo que é inequívoco na análise de ambas as imagens é que as crianças realizam um jogo simbólico com significados que parecem ser muito aproximados: 
ambos os grupos se confinam a um espaço de abrigo imaginário onde uma das meninas, em cada contexto, parece espreitar o mundo assumindo o papel de "messias". Aquilo que difere visivelmente nesta brincadeira de faz de conta são os materiais que suportam a história que nos é contada: as paredes, portas e janelas destas casas de fazer de conta; assim como muito provavelmente diferem as mensagens que possam chegar a um e outro lugar.

Figuras 11 e 12 - Brincadeiras com bonecas
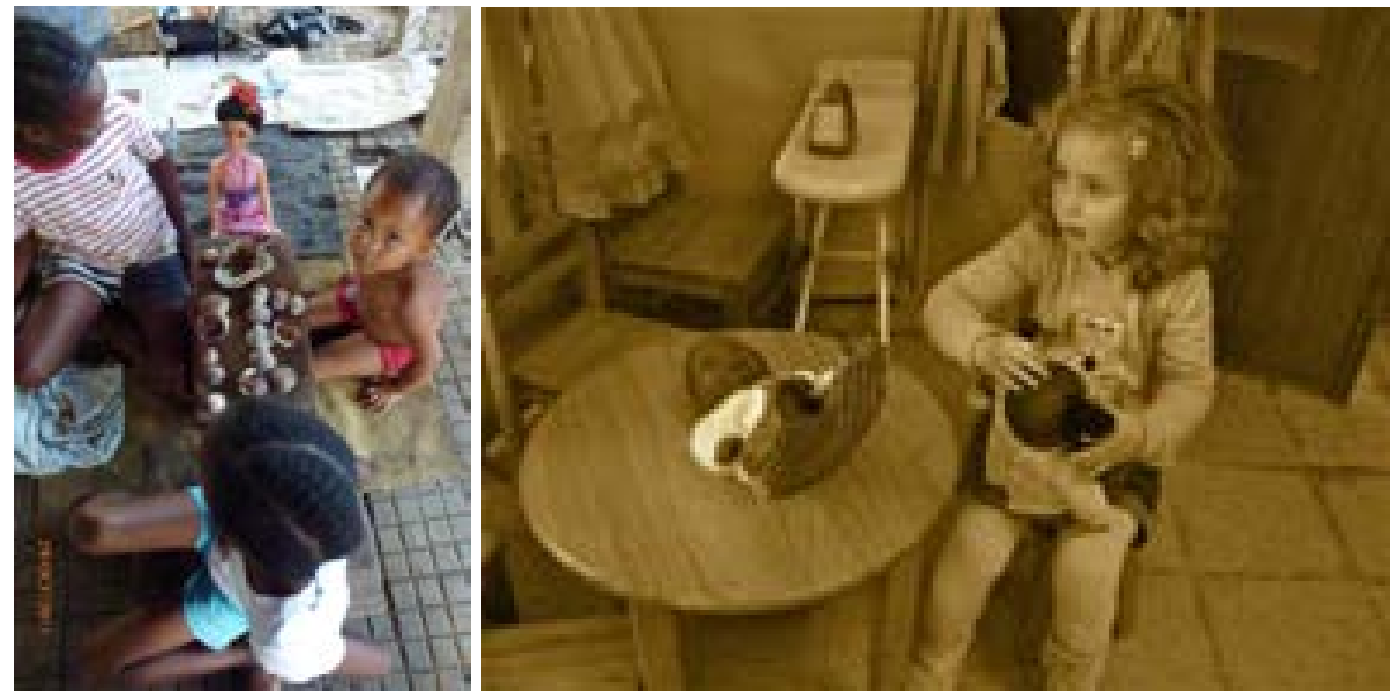

Fonte: registo das investigadoras.

Nas imagens selecionadas, as bonecas inserem-se no universo dos jogos de faz-de-conta das crianças, fazendo parte de um jogo simbólico idealizado pelo grupo de crianças cujos princípios e regras são entre elas partilhadas e os papéis sociais desempenhados são também negociados. As crianças santomenses simulam um almoço típico que costuma ser realizado nos quintais das casas em São Tomé e Príncipe (Foto no 11 ) com muita importância nas comunidades como momentos de convívio entre gerações. Na brincadeira representada nesta fotografia, é significativo que as crianças partilhem a mesa de refeição com uma boneca branca, que possui vestes, penteado e maquilhagem de estilo oriental. A criança portuguesa escolhe para objecto do seu afecto e cuidados dois bebés de pele negra (Figura 12), disponibilizados na área de faz-de-conta da sua sala de actividades. As relações com os outros, a necessidade de pertença a um grupo de pares e a reinterpretação de papéis sociais são visíveis na fala desta criança quando legenda a sua foto: 
"Eu estava a brincar com os bonecos do faz de conta... com as minhas colegas... e brinquei com... os bonecos a fazer festinhas... e também estava a brincar com a Mariana e com a Joana e com a Adriana... e o Francisco era o pai”.

Tratando-se em ambos os casos de brincadeiras de faz-de-conta com bonecas, as formas como as crianças escolhem brincar com as bonecas diferem de acordo com o quotidiano das suas sociedades: as crianças santomenses tratam esta boneca como um convidado na mesa de uma festa ritual santomense e a criança portuguesa assume o papel de cuidadora, mãe carinhosa e esposa. As duas situações evidenciam a forma como as crianças exprimem a cultura societal em que se inserem e veiculam formas especificamente infantis de representar os seus mundos, influenciadas ambas pelo tipo de bonecas disponibilizados pelos adultos em cada contexto.

\section{Fórmulas do brincar}

Figuras 13 e 14 - Brincadeiras com carrinhos
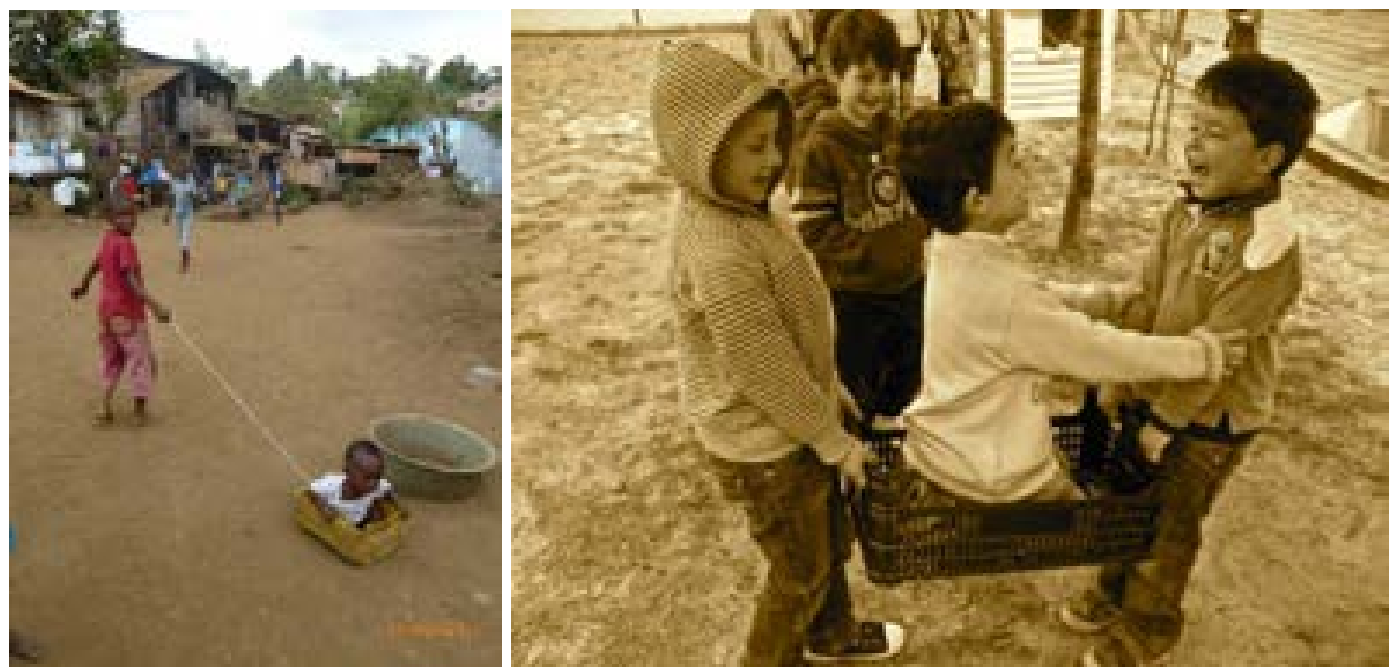

Fonte: registo das investigadoras.

Nesta brincadeira em que são transportados, como se fossem cargas, a organização e entendimento entre as crianças envolvidas (assunção das regras, respeito pela idade, habilidade e requisitos físicos de cada um - hierarquia) é fundamental. Essa atividade pode ser observada com alguma frequência entre os rapazes santomenses (Figura 13), sendo esse meio de transporte manipulado pelos rapazes mais velhos e apenas os rapazes mais novos são transportados, podendo ser esta 
também uma forma de acautelar o seu bom estado, pois este brinquedo, e outros similares, servem também (sobretudo?) para o transporte de diversos bens para a realização de "recados" aos adultos: trazer água para casa, comprar algum bem na quitanda ou no mercado, carregar lenha, etc.. $\mathrm{Na}$ análise contextualizada das brincadeiras dos rapazes portugueses percebemos que essa é uma brincadeira inusitada e inédita, surgida da disponibilidade de uma caixa de fruta deixada pela cozinheira da escola e, assim, também da liberdade de brincar oferecida pelos adultos da instituição a estes rapazes, no espaço exterior, onde a imaginação é fértil, livre e útil ao movimento corporal (Figura 14).

A diferença entre as brincadeiras desses rapazes nas duas latitudes está, sobretudo, no entendimento que cada grupo de crianças tem dos princípios de realização desta atividade lúdica, ou da sua pragmática: inventar meios de transporte, transportar e ser transportado; e, subsequentemente, das regras que existem, criaram ou vão criando nos diferentes contextos de execução da brincadeira - embora seja inegável a diversão causada por este tipo de brincadeira, que se realiza também apenas entre rapazes em ambos os contextos.

Figruas 15 e 16 - Brincadeiras com moluscos
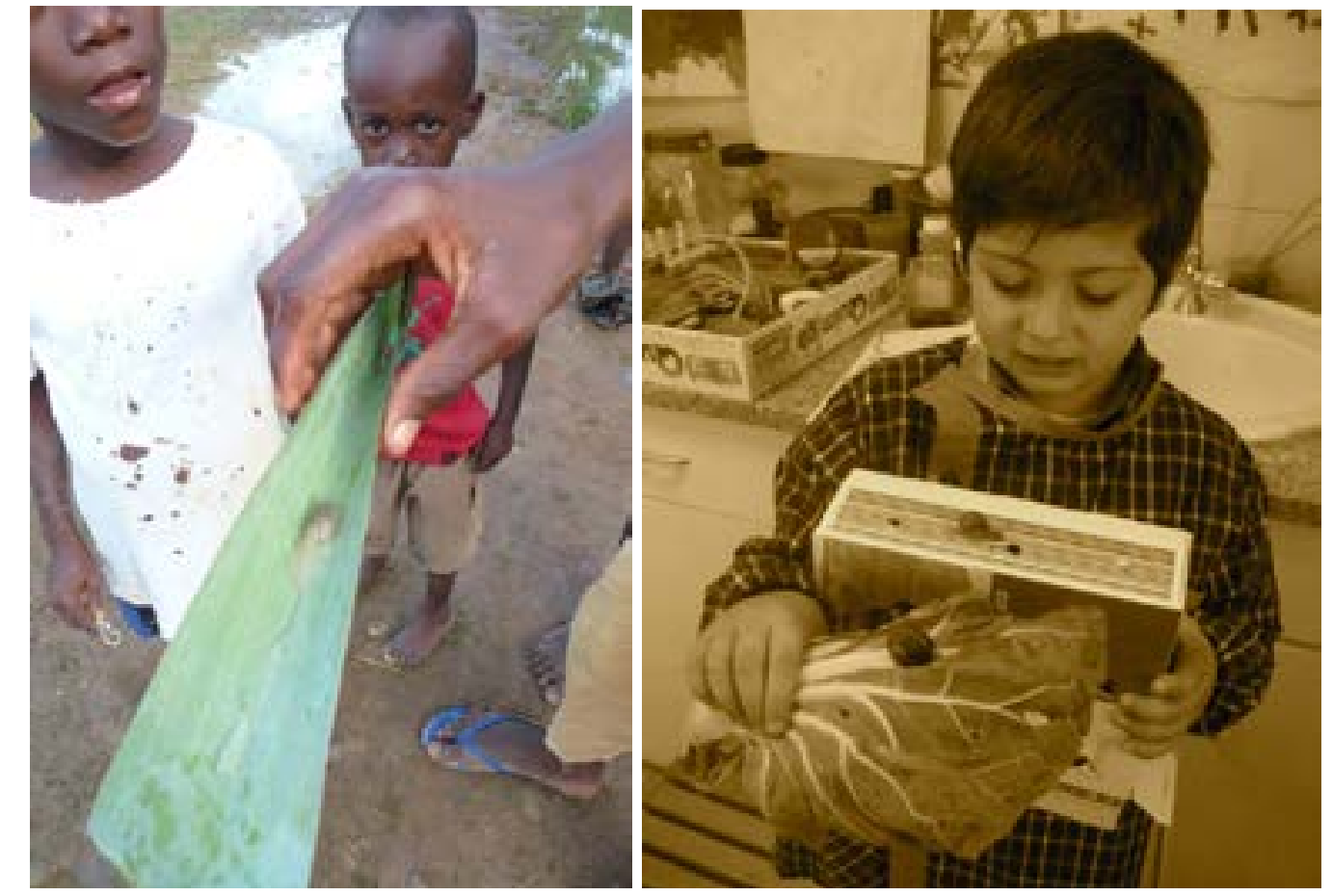

Fonte: registo das investigadoras. 
Nas imagens selecionadas, os rostos das crianças revelam o seu fascínio atento pelo mundo natural que as rodeia, e que em ambos os contextos têm moluscos como protagonistas. Essas formas de interagir com o mundo animal, caçando, pescando e observando atentamente é algo comum nas brincadeiras das crianças que aqui estão representadas. Em São Tomé e Príncipe, as crianças descobrem esses seres vivos nas poças de lama deixadas pelos dilúvios, frequentes numa determinada época do ano, no âmbito de uma brincadeira de "fazer de conta que se pesca". Nesses momentos lúdicos é possível observar as crianças que interagem, questionando soluções, procurando materiais, ou no arranjo de estratégias para que a pescaria seja bem-sucedida. Após o cativeiro diversificam-se as observações do grupo de crianças, cada vez mais atentas a tão prestigiados e microscópicos tesouros (Figura 15). A criança portuguesa ampara e observa, da mesma forma maravilhada, os caracóis que descobriu no recreio e que levou para a sala, desencadeando todo um processo que envolveu outras crianças e os adultos no fornecimento de alimento e de condições de sobrevivência aos caracóis; o seu fascínio por estes animais - que repugnavam outros adultos, inclusive a sua mãe - o que despoletou mesmo um projeto de investigação (Figura 16).

A importância de brincar e observar atentamente esses seres vivos parece ser similar para essas crianças, sendo os princípios para que ela aconteça, contudo, diversos: num contexto foram descobertos, noutro são mostrados; num momento são pescados pelas crianças, noutro são obtidos pela mão do adulto; assim como são libertados num contexto e mantidos em cativeiro no outro, por exemplo. Percebemos o interesse comum das crianças pelo mundo animal, mas que a fantasia da realidade pelas crianças pode alavancar e justificar de mil e uma formas diferentes: as crianças santomenses "pescam" por diversão os moluscos nas poças de lama; e as crianças portuguesas cuidam dos caracóis que passaram a ser seus "companheiros" durante todo um ano letivo.

\section{Conclusões}

As fotografias escolhidas para serem aqui analisadas mostram-nos crianças que brincam e ajudam-nos a perceber a transversalidade do divertimento e da vertigem desses momentos. A sua análise sugere brincadeiras universalmente reconhecíveis com materiais naturais (vegetais ou animais), materiais de desperdício (nem sempre com brinquedos), ou com o próprio corpo. Verifica-se, ainda, a escolha de jogos com princípios incontestados pelos companheiros de jogo e com regras es- 
tabelecidas e conhecidas pelos grupos de crianças, assim como a escolha de lugares para brincar. Ou seja, no âmbito das culturas lúdicas infantis existem brincadeiras, jogos e brinquedos que surgem como eleitos das crianças independentemente da latitude onde ocorrem.

Percebe-se que algumas brincadeiras são escolhidas em ambos os contextos geográficos por meninos e outras escolhidas apenas por meninas, participadas pelas crianças mais velhas ou pelas crianças mais novas, exigindo algumas delas o prévio conhecimento de regras e formas de jogar, elas próprias universalizadas. A par disso, uma análise mais aprofundada deixa-nos vislumbrar um complexo intricado de ações e interações que, fazendo parte de ambos os mundos das crianças, possuem leituras diferentes de acordo com o contexto geográfico, natural, económico, social e cultural, assim como com as relações estabelecidas (ou não) com os adultos e entre as crianças com as suas diferenças etárias e de género. Ou seja, descobrimos que as especificidades da brincadeira da criança santomense e da criança portuguesa, assim como os significados atribuídos à natureza da atividade, ao seu desenrolar e produções finais, estão profundamente ligados ao contexto social, econômico e cultural onde ocorrem (SARMENTO, 2004).

Os valores mobilizados e os significados atribuídos pelas crianças às suas ações, o desenvolvimento de linguagens para comunicar, a apresentação de normas e a definição de regras em cada contexto lúdico (jogo, brincadeira de faz-de-conta, brinquedo, etc.) definem as características das ordens sociais instituídas pelas crianças e instituintes da infância em cada contexto relacional (FERREIRA, 2004). Embora as crianças portuguesas e santomenses pertençam a culturas diferentes, heterogéneas e complexas, elas contribuem igualmente para a construção das culturas da infância e deste ponto de vista existe uma "universalidade das culturas infantis" (SARMENTO, 2004, p. 22). Na linguagem da sociologia da infância, diremos que se reafirma a categoria estrutural da Infância porque em todos os casos se trata de crianças que brincam e se confirma a pluralidade de infâncias pelas especificidades que o brincar assume em cada contexto, ou como nos diz Qvortrup: "[...] a infância como categoria não se dissolve porque existe uma pluralidade de infâncias; ao contrário, confirma-se por meio destas" (2010, p. 1133).

O direito de brincar é universal e, normativamente, proclamado pelos adultos, mas são as crianças que nos especificam como querem, gostam e qual é o sentido que o brincar faz localmente, tal como nos foi possível perceber pelo mapeamento das suas culturas lúdicas. Buscar os saberes junto das crianças implica que nos deixemos embrenhar na especificidade dos seus universos de vida para constatar que 
na diversidade dos mundos sociais e culturais da infância encontramos a universal peculiaridade de estar sempre a falar de crianças e que estas crianças sempre brincam. Inspirados em dois importantes autores na área da Infância, diremos que com "[... ] um mundo de diferenças: de condição social, de contexto, de valores, de referências simbólicas, de expectativas e possibilidades [...]" (Sarmento, 2003:53) todas as crianças brincam e enquanto brinca "[...] a criança em qualquer parte do mundo age com o mesmo instinto de magia e felicidade que é a própria expressão da vida e constitui a relação eterna entre o homem e o conhecimento do mundo" (Lambadaridou-Pathou, s/d apud AMADO, 1998, p. 30).

Essa abordagem denuncia a importância da contextualização das análises que se possam realizar sobre as brincadeiras, mas sobretudo a importância de considerar a escuta das crianças sobre esta matéria na delineação de estratégias e implementação de programas de estímulo à brincadeira e ao uso dos brinquedos, ou para a efetivação do direito a brincar em cada sociedade. A participação plena das crianças na vida cultural das suas sociedades através da promoção do direito a brincar concretiza-se quando direito a brincar é promovido com respeito ao contexto social específico onde ocorre, ou seja, quando os adultos se predispõem a (re)conhecer o lugar a partir do qual as crianças vêm o mundo e entender os significados que elas atribuem ao que as rodeia, ou quando os adultos se permitem identificar as culturas da infância e reconhecer a sua autonomia (CORSARO, 1999; SARMENTO, 2000).

Concluiremos dizendo que a escuta das crianças na liberdade das suas brincadeiras quotidianas pode ser precioso guia para os adultos interessados em fazer cumprir o direito de brincar. Antes de construir muros, equipar espaços e contratar profissionais adultos para a vigilância da brincadeira, valerá a pena refletir sobre a simplicidade - e gratuitidade - das demandas das crianças. E sempre observamos largos sorrisos e apontamentos de bem-estar espontâneo. Sugerimos que proclamar, respeitar e promover o direito universal do brincar da criança só terá sentido se as brincadeiras das crianças se realizarem no seio da pluralidade das suas culturas infantis e todos os esforços para a concretização desse direito devem basear-se na ideia de localização das brincadeiras: as formas diversas como as crianças brincam e gostam de brincar é que torna universal o brincar e o direito de todas as crianças a fazê-lo - ou a diversidade como estruturante da universalidade das culturas da infância. 
1 Tese 1 : "A Infância na Latitude Zero - As brincadeiras da criança 'global' africana" - Bolsa de Investigação da Fundação da Ciência e Tecnologia, no âmbito do QREN - POPH - Tipologia 4.1 - Formação Avançada, comparticipada pelo Fundo Social Europeu e por fundos nacionais do MCTES com a referência: SFRH/ BD/71978/2010. ; Tese 2: "E de dentro do circo saiu um passarhomem, metade homem e metade pássaro" As Culturas Infantis no Jardim de Infância. Tese Doutoramento em Estudos da Criança.

2 De acordo com a Metodologia de trabalho MEM - Movimento da Escola Moderna -, adoptada pela educadora no Jardim de Infância de Estrada/Agrupamentos de Escolas Amadeo de Souza Cardoso, Amarante-Portugal.

\section{Referências}

AMADO, J.Brincar aos olhos de Brueghel. In: PAIS, N. SANTOS, L. VIEGAS F. (Ed.), Cultura lúdica, tradição e Modernidade - Cadernos de Actividade Lúdica. Lisboa: Ed. Instituto de Apoio à Criança, 1998. p. 25-35.

AMADO, J. Universo dos Brinquedos Populares. Coimbra: Quarteto Editora, 2002.

BARRA, S.M.M. A Infância na Latitude Zero: as brincadeiras da criança 'global' africana. Tese de Doutoramento em Estudos da Criança, área de Sociologia da Infância. Instituto de Educação. Braga: Universidade do Minho, 2016.

BROUGÉRE, G. Brinquedo e cultura. São Paulo: Cortez, 1994.

BUCKINGHAM, D. Children and Television. In: QVORTRUP, J.; CORSARO, W. A.; HONIG, M. S. (Eds.). The Palgrave Handbook of Childhood Studies. UK: Palgrave MacMillan, 2011. p. 347-359.

BURMAN, E. (1996). Local, Global or Globalized?: Child Development and International Child. Childhood, v. 3, n. 45, 1996.

CALLOIS, R. Os Jogos e os Homens. Lisboa: Cotovia, 1990.

COLONNA, E. Eu é que fico com a minha irmã - vida quotidiana das crianças na periferia de Maputo. Tese de Doutoramento em Estudos da Criança, área de Sociologia da Infância. Instituto de Educação. Braga: Universidade do Minho, 2012.

COOK, D. Children as consumers. Em J. Qvortrup, W. A. Corsaro \& MS. Honig (Eds.). The Palgrave Handbook of Childhood Studies. UK: Palgrave MacMillan, 2011. p. 332-346.

CORSARO, W. (1985). Friendship and peer culture in the early years. Norwood: Ablex, 1985.

CORSARO, W. The Sociology of Childhood. California: Pine Forge, 1997.

CORSARO, W. (2002). A reprodução interpretativa no brincar ao faz-de-conta das crianças. Educação, Sociedade e Cultura, Porto, 2002, v. 17, p. 113-134.

DELALANDE, J. La récréation:Le temps d'apprendre entre enfants. Enfances \& Psy, n. 24, p. 71-80, 2004,

DENZIN, N. Childhood Socialization. S. Francisco: Jossey-Bass, 1977. 
FERNANDES, A. Os Direitos da Criança no Contexto das Instituições Democráticas. Em Formosinho, J. (coord.). A Criança na Sociedade Contemporânea (pp28-41). Lisboa: Universidade Aberta, 2004.

FERREIRA M. Do 'Avesso' do Brincar ou...as Relações entre Pares, as Rotinas da Cultura Infantil e a Construção da(s) Ordem(ens) Social(ais) Instituinte(s) das Crianças no Jardim-de-Infância. Em M. J. Sarmento \& A. Cerisara (orgs.). Crianças e Miúdos - Perspectivas sociopedagógicas da infância e educação. Porto: Ed. ASA, 2004. p. 55-104.

Ferreira, M. \& Sarmento, M. (2008). Subjetividade e bem-estar das crianças: (In)visibilidade e voz. Revista Eletrônica de Educação, São Carlos/SP, v. 2, n. 2, p. 60-91.

FRONES, I. Childhood: Leisure, Culture and Peers. Em J. Qvortrup, W. A. Corsaro \& MS. Honig (Eds.). The Palgrave Handbook of Childhood Studies (pp. 273 - 286). UK: Palgrave MacMillan, 2011.

HUIZINGA, J. Homo Ludens. São Paulo: Perspectiva, 1980.

KOPPELE, B. Crianças de rua em Angola: caracterização das suas expressões culturais. Dissertação de Mestrado. Instituto de Educação. Braga: Universidade do Minho, 2012.

JAMES, A. Childhood Identities: self and social relationships in the experience of the child. Edinburgh: Edinburgh University Press, 1993.

JAMES, A. Play in Childhood - an anthropological perspective. Child Psychology and Psychiatry Review, Cambridge, n. 3, p. 1-6, 1998.

JAMES, A.; JENKS, C.; PROUT, A. Theorizing Childhood. Polity Press: Cambridge, 1998.

LOPES, M. G. Jogos na Educação: criar, fazer, jogar. São Paulo: Cortez, 1998.

MALINOWSKI, B. Coral Gardens and Their Magic: A Study of the Methods of Tilling the Soil and of Agricultural Rites in the Trobriand Islands. United Kingdom: Routledge, 1935.

QVORTRUP, J. A Tentação da Diversidade - e seus riscos. Educação e Sociedade, n. 31, v. 113, 2010. p. 1121-1136.

ROCHA, N. \& Costa, M. da (2014). Epistemologias do sul e estudos sociais da infância: crianças e ancestralidade africana na escola. Em M. M. Baptista \& S. V. Maia (cords.). Atas do IV Congresso Internacional em Estudos Culturais: Colonialismos, Pós-Colonialismos e Lusofonias Aveiro: Ed. Programa Doutoral em Estudos Culturais da Universidade de Aveiro e Universidade do Minho. p. 528-534. Disponível em: http://estudosculturais.com/congressos/ivcongresso/ wp-content/uploads/2014/04/atas-PT-final.pdff. Acesso em: set. 2019.

SAMPAIO, M. M. "E de dentro do circo saiu um passarhomem, metade homem e metade pássaro”. As Culturas Infantis no Jardim de Infância. Tese Doutoramento em Estudos da Criança, área de Sociologia da Infância. Braga: Universidade do Minho, 2018.

SARMENTO, M. J. Os Ofícios da Criança. Em Vários. Os Mundos Sociais e Culturais da Infância (v II, p. 125-145). Braga: Instituto de Estudos da Criança da Universidade do Minho, 2000.

SARMENTO, M. (2003). Imaginário e Culturas da Infância. Cadernos de Educação, v. 12, n. 21, p. 51-69. 
SARMENTO, M. J. As culturas da infância nas encruzilhadas da Segunda Modernidade. Em M. J. Sarmento \& A. Cerisara (org.). Crianças e Miúdos: Perspectivas Sociopedagógicas da Infância e Educação Porto: Edições Asa, 2004. p. 9-34.

SARMENTO, M. J. Crianças africanas: os desafios da sociologia da infância pós-colonial. Oficinas de Sociologia da Infância. Departamento de Ciências Sociais da Educação/Instituto de Educação. Braga: Universidade do Minho, 2013.

SILVA, N. Jogos, Brinquedos e Brincadeiras-Trajetos intergeracionais. Barbudo-Vila Verde : ATAHCA, 2011.

SILVA, N. Infância, Cultura e Ludicidade: Coisas de Crianças. Em L. V. Dornelles \& N. Fernandes (org.). Perspetivas sociológicas e educacionais em estudos da criança: as marcas das dialogicidades luso-brasileiras (pp. 659-684). Editor: Centro de Investigação em Estudos da Criança, Universidade do Minho, Braga, 2012. Disponível on-line: http://www.ciec-uminho.org/document-os/ebooks/2307/. Acesso em: set. 2019.

STEINBERG, S.. Kindercultura: a construção da infância pelas grandes corporações. In: SILVA L.; AZEVEDO, J.; SANTOS, E. (org.) Identidade Social e a construção do conhecimento. Porto Alegre: SMED/RS, 1997.

TOMÁS, C. FERNANDES, N. (org.) Brincar, Brinquedos e Brincadeiras: modos de ser criança nos países de língua oficial portuguesa. Maringá: UEM, 2014.

TOMÁS, C.; SOARES, N. Direitos da Criança em Portugal: os desassossegos dos riscos na/da Infância. 2011. Disponível em: http://repositorium.sdum.uminho.pt/bitstream/1822/15070/1/ Direitos\%20da\%20crian\%C3\%A7a\%20em\%20Portugal_os\%20desassossegos\%20dos\%20direitos $\% 20 \mathrm{da} \% 20$ crian $\% \mathrm{C} 3 \% \mathrm{~A} 7 \mathrm{a} \% 20 \mathrm{ao} \% 20$ longo\%20de $\% 20$ uma $\% 20 \mathrm{~d} \% \mathrm{C} 3 \%$ A9cada.pdff. Acesso em: set. 2019.

UN Committee on the Rights of the Child (CRC) (2013). General comment no. 17, on the right of the child to rest, leisure, play, recreational activities, cultural life and the arts (art. $\left.31^{\circ}\right)$. Disponível em : https://www.refworld.org/docid/51ef9bcc4.html. Acesso em: set. 2019.

UNICEF - Convenção sobre os Direitos da Criança - CDC (1989). [on-line]. Disponível em: https://www.unicef.pt/media/1206/0-convencao_direitos_crianca2004.pdf. Acesso em: set. 2019. 